\title{
EXPERIMENTAL STUDY OF THE FORMING POSSIBILITY OF ISF PROCESS FOR PVC PLASTIC SHEET
}

\author{
Nguyen Van Nang ${ }^{(1)}$, Nguyen Thanh Nam ${ }^{(1)}$, Le Khanh Dien ${ }^{(2)}$, \\ Nguyen Thien Binh ${ }^{(1)}$, Nguyen Minh Tu${ }^{(1)}$ \\ (1) Digital Controlling and System Engineering Lab - DCSELAB \\ (2) University of Technology, VNU-HCM \\ (Manuscript Received on April $5^{\text {th }}, 2012$, Manuscript Revised November 20 ${ }^{\text {rd }}$, 2012)
}

ABSTRACTS: This article presents an experimental study examining the effects of technological parameters to the ISF process on PVC material such as : tool diameter d, tool step depth $\Delta z$, feed rate $f$ and forming temperature $T$, thereby the determining the limiting value of angular distortion $\alpha_{\max }$.

Keyword: Experimental study, ISF process, forming possibility of PVC sheets.

\section{INTRODUCTION}

Polymer materials hold a significant proportion of civil and industrial products. The traditional technique to produce polymer products based largely on the heating process shaping - cooling, are conducted at yield or flow status to mould and is only suitable for mass production because of high energy and equipment cost. Thus, to meet the requirements for reducing cycle time and suitable to produce single pieces, small batch, rapid prototyping, we need to have innovative technologies to make new manufacturing technique flexible.
Incremental Sheet Forming (ISF) a new sheet forming process has been developed in recent years. Two types of this technology is Single point incremental forming (SPIF) and Two point incremental forming (TPIF). At first the process was studied on metal materials, later the scope was expanded on the polymer, composite. The ISF technogogy equipment is often a simple frame for clamping sheet material, while the forming is done using a device moving along the contour that is programmed by the $\mathrm{CNC}$ machine or industrial robot (Figure 1). 


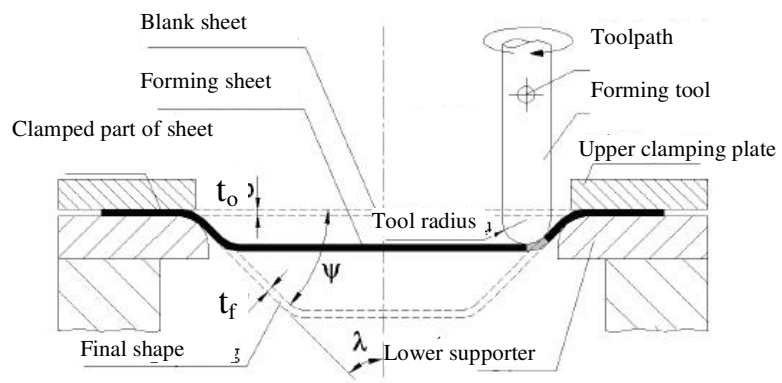

Fig.1. SPIF process [4] In the ISF process on thermoplastic sheet or PVC sheet in particular, there are many parameters affecting the forming ability of the ISF: tool diameter $\mathrm{d}$, tool step depth $\Delta \mathrm{z}$, feed rate $\mathrm{f}$ and forming temperature $\mathrm{T}$, thereby determining the limiting value of angular distortion $\alpha$ max.

\section{EXPERIMENT MODEL}

\subsection{Cad model}

According to a study has published [5], a curved cone part with curved generatrix was selected to test the forming ability. Geometry of the part is designed to study all the angles from 0 to $90^{\circ}$. When the thickness of the part changes following the cosine rule and the slope of part increases with depth, the analysis area is limited to an angle smaller than $90^{\circ}$ - Figure 2.

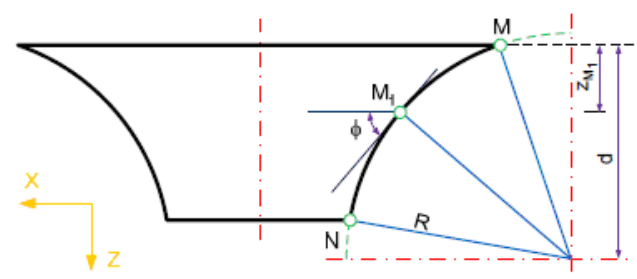

Fig.2. Curved cone contour [5]

Figure 2 shows generatrix of the part is examined through experiments. Analyzed areas to be are drawn outside arc MN. Wall angular $\Phi$ of the point on the generatrix determined by the tangent of the contour, could be calculated with formula:

$$
\Phi=\arccos (\mathrm{x} / \mathrm{R})
$$

$\mathrm{R}$ is the radius of the arc and $\mathrm{x}$ is the coordinate perpendicular is given by:

$$
\mathrm{X}=\mathrm{d}-\mathrm{z}_{\mathrm{M} 1} .
$$

The value of $d$ is the maximum height of the cone and $z_{M 1}$ is the position of the tool when damage occurs. This value is recorded by the interaction of the $\mathrm{CNC}$ machine control device and be re-examined by the use of coordinate measuring machines (CMM).

Changing range of $\alpha$ from the initial deformation angle $\alpha_{0}$ increases continuously to the largest deformation angle $\alpha_{\max } . \alpha_{\max }$ is the received value when the wrinkle area, crushing force, or the crack appears, Figure 3.

\section{Trang 6}




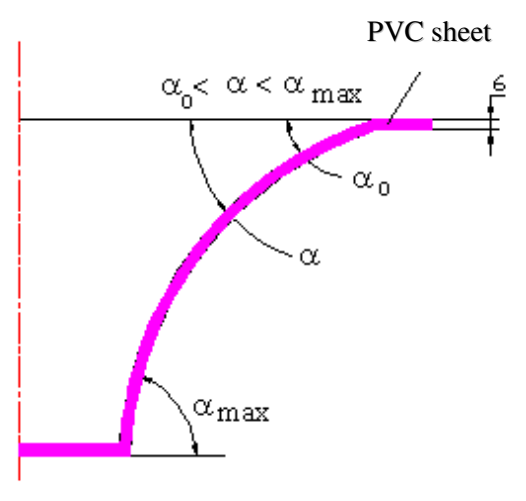

Fig.3. The increasing of deformation angle $\boldsymbol{\alpha}$ with depth in ISF process [6]

\subsection{Changing Parameter}

Influence of parameters needs to examine are the step-down tool $\Delta \mathrm{z}(\mathrm{mm})$, feed rate $\mathrm{f}$ (mm per minute), forming temperature $\mathrm{T}\left({ }^{0} \mathrm{C}\right)$, tool diameter $\mathrm{d}(\mathrm{mm})$.

\section{Tool step depth $\Delta z(\mathrm{~mm})$ :}

$\Delta \mathrm{z}$ impacts significantly on the forming ability. Large down step $\Delta \mathrm{z}$ leads to large deformation force that causes difficulty for the forming ability. If tool step depth is small, forming force get smaller but can still deform workpiece plate. However, $\Delta \mathrm{z}$ should not be too small (lower than $0.3 \mathrm{~mm}$ - for $2 \mathrm{~mm}$ PVC sheet) because the part will soon be torn due by sheet thickness after shaping is pretty thin when tool stretch workpiece sheet.

Combine these factors with the capacity allowed on the CNC machine, the value of $\Delta z$ was chosen from $0.4-1.2 \mathrm{~mm}$.

\section{Tool diameter d (mm)}

Tools diameter $d$ is related to the forming force because of stress and tearing. When the tool diameter increases, the process is the same as the traditional press, thus reducing the forming limit. However, when using the tool with the small radius, it will easily penetrate into the sheet and cause peeling. So the ability of forming is significantly reduced if the radius of the forming tools is too small.

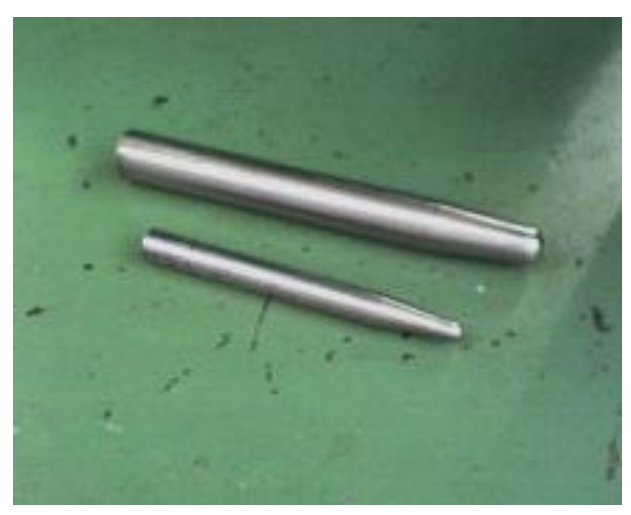

Fig.4. The tools has a diameter $d=6,12 \mathrm{~mm}$ used in the experiments

In addition, the diameter of tools is also driven by engine capacity. Along with the quantity $\Delta \mathrm{z}, \mathrm{f}$, it must meet the requirements that machine work smoothly, no vibration in the process of forming. The value $d=6$ to 12 $\mathrm{mm}$ was chosen in this study, Figure 4.

\section{Tool feed rate $\mathbf{f}$ ( $\mathrm{mm}$ per minute)}

This parameter mainly affects the productivity. Similar to tool step down $\Delta \mathrm{z}$, depending on the value of $f$ large or small the productivity will be high or low respectively.

In the ISF process forming the thermoplastic material, the wear caused by friction of the tools with PVC material is negligible because of the flexibility of plastic. This is an outstanding advantage of technology 
to reduce costs when compared with application on metallic materials. To ensure the operation does not exceed the capacity of the machine, as well as the productivity of processing the applied value $f$ in experimental studies in the range $1000-2500 \mathrm{~mm} / \mathrm{min}$.

\section{Forming Temperature $\mathbf{T}\left({ }^{0} \mathrm{C}\right)$}

Temperature changes the mechanical properties of PVC materials (softened or hardened), it impacted significantly on the deformation of the PVC. Low temperature makes the forming ability low. Conversely, when the temperature increases the deformation capacity is higher but at the same time also receiving greater springback. To determine the optimal temperature range for the ability of the workpiece plate deformation to be the greatest, the need of performing experiments at several different temperatures. The result is the largest deformation capacity obtained at $50^{\circ} \mathrm{C}$ temperature. Around this temperature $\quad\left(30-50^{\circ} \mathrm{C}\right)$ is considered appropriate to conduct experimental, Figure 5.

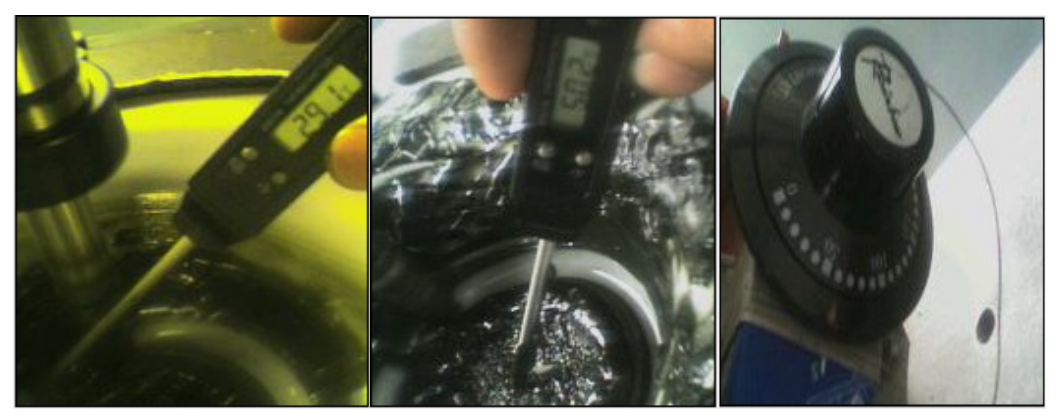

Fig.5. Set temperature and actual temperature at $30^{\circ} \mathrm{C}$ and $50^{\circ} \mathrm{C}$

\section{a) Spindle speed $\mathbf{n}$ (= 900 round per $\min )$}

Spindle speed reduces sliding friction at the contact surface between the plates and tools, thus reducing tools wear and reducing the forming force. The rotational speed $\mathrm{n}$ is related to the temperature set value, if the difference of the temperature is large, the ability of forming significantly reduces.

\section{b) Lubrication Cooling Solution}

Lubricating the contact area between tools and workpiece surface sheet, and also works keeps the temperature stable at the molding process. However, friction remains substantially between the tools and plastic sheet. Without lubrication, temperature of the plate surface is very hot and peeling of the burrs, details will be damaged, which means deformation ability gets lower. Lubricants are used as grease, oil SAE 40 or SAE 60, with coolant emulsion to keep constant temperature during forming shows in Figure 6.

\section{Trang 8}




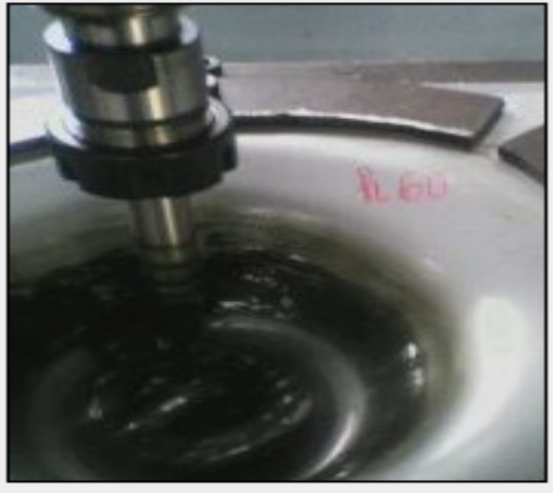

Fig.6. Mixed lubrication grease - oil SAE 40

c) Sheet thickness $(=2 \mathrm{~mm})$

PVC sheet used in the experiments has the thickness of $2 \mathrm{~mm}$. The selection of this value related to the properties of plastic sheet and the limited capacity of the machine.

\section{DEFORMATION ABILITY $\alpha$}

\subsection{Experiment}

In the process of conducting experiments, the PVC sheet with uniform thickness of $2 \mathrm{~mm}$ was used.

The experiments survey was conducted on a dedicated CNC machine include: 1/ a clamp holding the support plate behind the upper clamp, 2/ single point forming tool, $3 /$ heating fixture, (Figure 7). PVC plates are fixed by clamping plates and shaped by forming tools. The path of the tool is built by CAM model using Pro / E software.

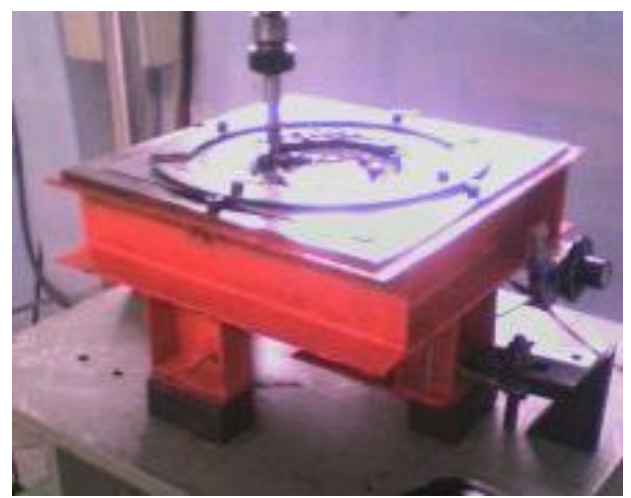

Fig.7. ISF process on PVC sheet

\subsection{Two experiment steps}

Detail sample to examine in the experiments has $\varnothing 200 \mathrm{~mm}$ diameter, depth $\mathrm{h}$ of $60 \mathrm{~mm}$. The process of running samples was carried out in 02 steps:

- First is the curved cone model, (Fig. 8). The forming is performed until the appearance of torsion or the tears. Measure the distance $\mathrm{z}$ at the position tearing position, we could determine the maximum angle of pull by the formula: $\cos \alpha=\frac{z}{R}$, Figure 9.

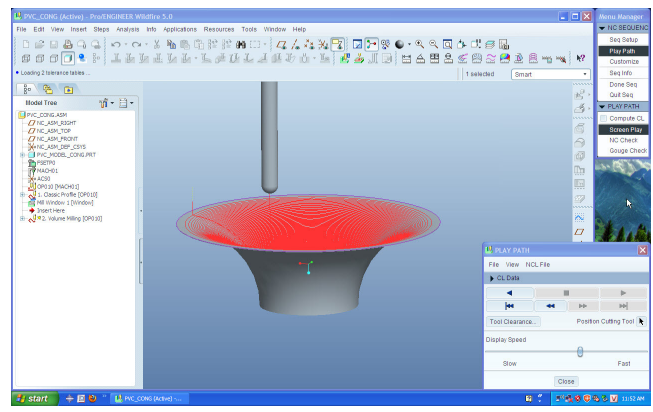

Fig.8. Curved cone model simulated on Pro / E with $\mathrm{h}=60 \mathrm{~mm}, \varnothing=200 \mathrm{~mm}$ 


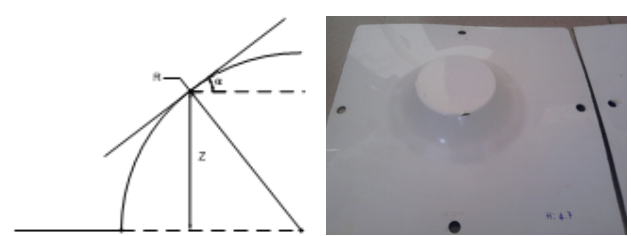

Fig.9. Model to calculate deformation angle

In some cases, when forming ability of plastic sheet is optimal, the details models after shaping is not twisted, or torn when $h=60 \mathrm{~mm}$, (Fig. 10).

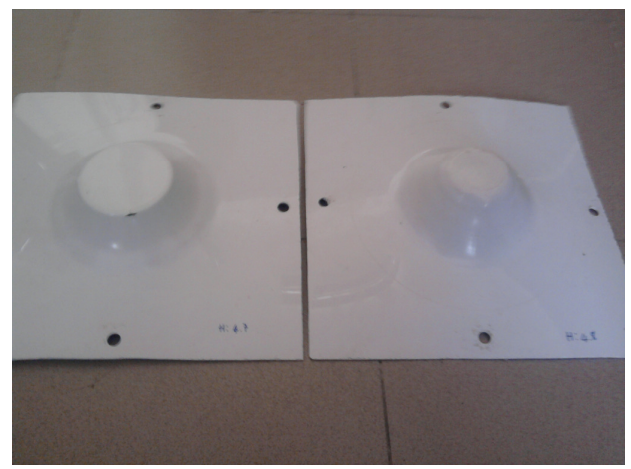

Fig.10. Details undamaged after reaching forming depth $\mathrm{h}=60 \mathrm{~mm}$

Verifying the maximum angle of deformation straight cone models, (Figure11). Based on $\alpha_{\max }$ values measured in the curved cone model that we test on straight cone model. Usually it has to reduce max value $\alpha$ until there is no twisting tearing, Figure $12 \mathrm{~b}$. Sometimes it could decrease from 3 to 5 degrees. If it is not torn then continue to increase 1 degree until tearing. Value of drag angle at the position twist or local corner tear start to appear called the largest deformation of the workpiece plate.

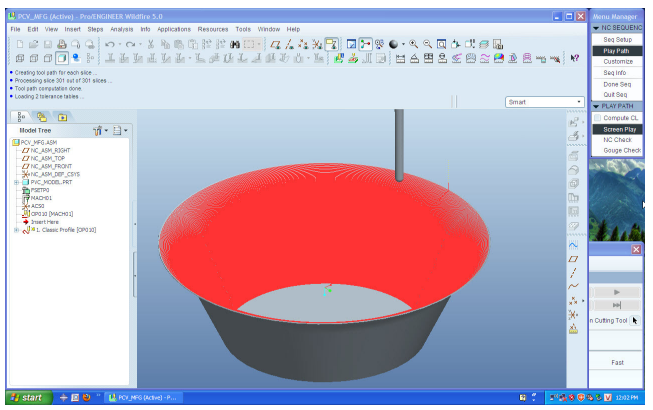

Fig.11. Straight cone model simulation on Pro / E for $\mathrm{h}=60 \mathrm{~mm}, \varnothing=200 \mathrm{~mm}$

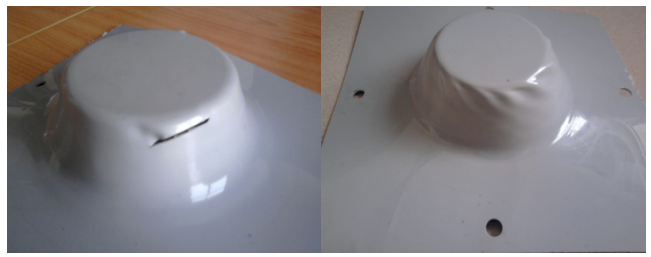

a)

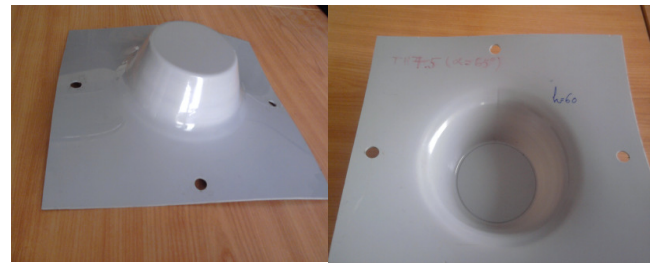

b)

Fig.12. Straight cone model is twisted, teared (a) and undamaged after reducing of drag angle (b)

\section{RESULT AND DISCUSSION}

Experiment separate factors used for the survey in this study. There are 08 experiments conducted on the cone curved model. Experiments result are given in Table 1. 
Table 1. Experimental Results

\begin{tabular}{|c|c|c|c|c|c|}
\hline \multirow{2}{*}{$\begin{array}{c}\text { Orde } \\
\mathbf{r}\end{array}$} & $\begin{array}{c}\text { Step depth } \\
\mathbf{\Delta z}(\mathbf{m m})\end{array}$ & $\begin{array}{c}\text { Tool diameter } \\
\mathbf{d}(\mathbf{m m})\end{array}$ & $\begin{array}{c}\text { Tool feed rate f } \\
\text { (mm per } \\
\text { min) }\end{array}$ & $\begin{array}{c}\text { Forming } \\
\text { temperatur } \\
\left.\text { e T ( }{ }^{\mathbf{0}} \mathbf{C}\right)\end{array}$ & $\begin{array}{c}\text { Result } \\
\text { Deformation } \\
\text { angle } \boldsymbol{\alpha}_{\text {max }} \mathbf{(}^{\mathbf{0}} \text { ) }\end{array}$ \\
\hline $\mathbf{1}$ & 0.4 & 6 & 1000 & 30 & 69 \\
\hline $\mathbf{2}$ & 1.2 & 6 & 1000 & 50 & 66 \\
\hline $\mathbf{3}$ & 0.4 & 12 & 1000 & 50 & 84 \\
\hline $\mathbf{4}$ & 1.2 & 12 & 1000 & 30 & 82 \\
\hline $\mathbf{5}$ & 0.4 & 6 & 2500 & 50 & 80 \\
\hline $\mathbf{6}$ & 1.2 & 6 & 2500 & 30 & 76 \\
\hline $\mathbf{7}$ & 0.4 & 12 & 2500 & 30 & 69 \\
\hline $\mathbf{8}$ & 1.2 & 12 & 2500 & 50 & 76 \\
\hline
\end{tabular}

The values of of drag angle deformation in the curved cone model are quite high, which is clearly shown in the table of results and images obtained after experiments, Figure 13.

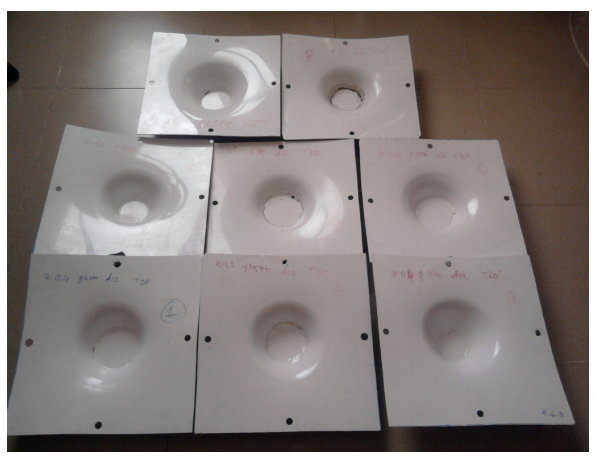

Fig.13. Some of the details after forming the curved cone model

After obtaining the value of drag angle from the experiments of curved cone model, a straight cone model is formed with this angle. In case of damage occur on the model, the higher angle will be used until the model is done. Otherwise, a decreasing angle will be applied to the model until the sheet material fall. In this case, the previous angle is obtained as maxium forming angle $\alpha_{\max }$.

Repeat the experiment 03 times for the selected angle for each case. This will conduct a total of 24 experiments, Figure 14. The order of 24 experiments on eight samples was randomly assigned to increase the reliability of the experiment. Results of experimental model for the straight cone are on Table 2. 
Table 2. Processing result of 8 experiment with 3 duplicated times

\begin{tabular}{|c|c|c|c|c|c|c|c|}
\hline \multirow{2}{*}{$\mathbf{N}^{0}$} & \multicolumn{4}{|c|}{ Input } & \multicolumn{3}{|c|}{ Result $\boldsymbol{\alpha}_{\max }$} \\
\hline & $\Delta \mathbf{z}(\mathrm{mm})$ & $\mathbf{d}(\mathrm{mm})$ & $\begin{array}{c}\mathbf{f}(\mathrm{mm} \text { per } \\
\min )\end{array}$ & $\mathbf{T}{ }^{0} \mathrm{C}$ & $\mathbf{y}_{1}$ & $\mathbf{y}_{2}$ & $\mathbf{y}_{3}$ \\
\hline 1 & 0.4 & 6 & 1000 & 30 & 50 & & \\
\hline 2 & 0.4 & 6 & 1000 & 30 & & 53 & \\
\hline 3 & 0.4 & 6 & 1000 & 30 & & & 53 \\
\hline 4 & 1.2 & 6 & 1000 & 50 & 65 & & \\
\hline 5 & 1.2 & 6 & 1000 & 50 & & 63 & \\
\hline 6 & 1.2 & 6 & 1000 & 50 & & & 63 \\
\hline 7 & 0.4 & 12 & 1000 & 50 & 65 & & \\
\hline 8 & 0.4 & 12 & 1000 & 50 & & 65 & \\
\hline 9 & 0.4 & 12 & 1000 & 50 & & & 66 \\
\hline 10 & 1.2 & 12 & 1000 & 30 & 60 & & \\
\hline 11 & 1.2 & 12 & 1000 & 30 & & 63 & \\
\hline 12 & 1.2 & 12 & 1000 & 30 & & & 60 \\
\hline 13 & 0.4 & 6 & 2500 & 50 & 65 & & \\
\hline 14 & 0.4 & 6 & 2500 & 50 & & 65 & \\
\hline 15 & 0.4 & 6 & 2500 & 50 & & & 65 \\
\hline 16 & 1.2 & 6 & 2500 & 30 & 65 & & \\
\hline 17 & 1.2 & 6 & 2500 & 30 & & 62 & \\
\hline 18 & 1.2 & 6 & 2500 & 30 & & & 62 \\
\hline 19 & 0.4 & 12 & 2500 & 30 & 55 & & \\
\hline 20 & 0.4 & 12 & 2500 & 30 & & 57 & \\
\hline 21 & 0.4 & 12 & 2500 & 30 & & & 57 \\
\hline 22 & 1.2 & 12 & 2500 & 50 & 65 & & \\
\hline 23 & 1.2 & 12 & 2500 & 50 & & 68 & \\
\hline 24 & 1.2 & 12 & 2500 & 50 & & & 66 \\
\hline
\end{tabular}

The process of repeated experiments for each case shows that the value of the angle does not change so much. However, in each different run mode, their values also have significant differences.

\section{Trang 12}




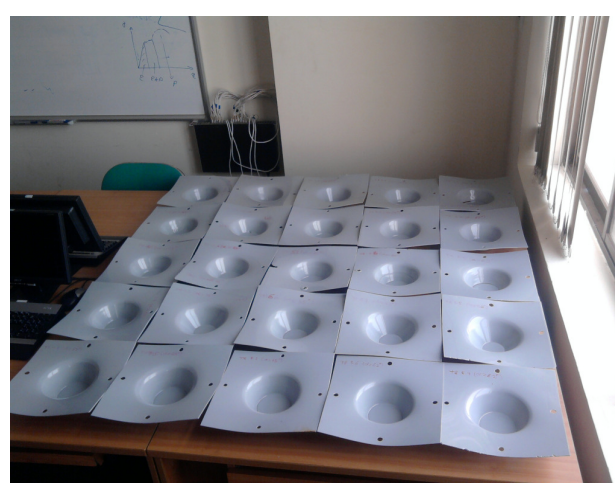

Fig.14. The details in the different run setting in the straight cone model

Our experimental results show that the forming ability increase with the one of the feed rate $\mathrm{f}$ and forming temperature $\mathrm{T}$ (when $\mathrm{T}=50^{\circ} \mathrm{C}, \mathrm{f}=2500 \mathrm{~mm}$ per $\mathrm{min}$, experimental result $\alpha_{\max }=65^{\circ}$ ). The biggest impact is $\mathrm{T}$, $\mathrm{f}$ has smaller impact.

Forming ability also increases with increasing tool step down $\Delta \mathrm{z}$ and tool diameter $\mathrm{d}$ (when $\mathrm{d}=12, \Delta \mathrm{z}=1.2$ value of the deformation angle in the experiments $\alpha_{\max }=63^{0}$ ). The largest impact is $\Delta z$ and $d$ has no significant effect.

\section{CONCLUSION}

With the work already done, the paper has solved the following problems:

Experiments show the influence of the parameters $\Delta \mathrm{z}, \mathrm{d}, \mathrm{f}$, and $\mathrm{T}$ to the deformation capacity of the PVC sheet. Successful experiments conduct on curved cone model and straight cone, determined angle $\alpha$ that the plastic deformation can reach $65^{\circ}$.

The experiments values of the project can be used to select the mode of machining of PVC sheet by ISF suitable for the purpose of forming. Determine the limited forming angle of ISF technology could be applied in machining of PVC sheet.

\title{
NGHIÊN CÚU THỰC NGHIỆM KHẢ NĂNG TẠO HÌNH TRONG QUI TRÌNH ISF TRÊN TẤM NHỤ̂A PVC
}

\author{
Nguyễn Văn Nang ${ }^{(1)}$, Nguyễn Thanh Nam ${ }^{(1)}$, Lê Khánh Điền ${ }^{(2)}$, Nguyễn Thiên Bình ${ }^{(1)}$ \\ (1) Phòng thí nghiệm Điều khiển số và Kỹ thuật hệ thống - Trường ĐH Bách Khoa \\ (2) Trường Đại họcBách Khoa - ĐHQG-HCM
}

TÓM TĂT: Bài báo trình bày một nghiên cứu thực nghiệm xem xét ảnh huởng của các thông số công nghệ trong qui trình ISF trên vật liệu nhựa PVC nhu đuờng kính dụng cu d, buớc xuống dụng cu $\Delta z$, tốc độ chạy dao $f$, và nhiệt độ tạo hình $T$ đến khả năng tạo hình a của phôi tấm, tì đó xác định giá trị giới hạn của góc biến dạng $\alpha_{\max }$ trong tạo hình ISF trên tấm nhựa PVC.

Tù khóa: Nghiên cúu thục nghiệm, Quy trình ISF, Khả năng tạo hình tấm PVC. 


\section{REFERENCES}

[1]. Kathryn Jackson, Julian Allwood,The mechanics of incremental sheet forming, Department of Engineering, University of Cambridge, 16 Mill Lane, Cambridge CB2 1RX, UK (2007).

[2]. Pohlak, M.; Küttner, R.; Majak, J.; Karjust, K. \& Sutt, A., Simulation of incremental eorming of sheet metal products - industrial engineering innovation as competitive edge for sme, Tallinn, Estonia (2004).

[3]. Pohlak, M.; Küttner, R.; Majak, J.; Karjust, K. \& Sutt, A., Simulation of incremental eorming of sheet metal products - industrial engineering innovation as competitive edge for sme, Tallinn, Estonia (2004).

[4]. Martins, P.A.F.'; Bay N. (1) ${ }^{\text {b,*; }}$; Skjoedt ${ }^{\mathrm{b}}$,M.; Silva, M.B. ${ }^{\mathrm{a}}$,Theory of single point incremental forming, ${ }^{\mathrm{a}} \mathrm{IDMEC}$, Instituto Superior Tecnico, TULisbon, Portugal; ${ }^{b}$ Department of Mechanical Engineering, Technical University of Denmark, Denmark(2008).

[5]. Emmens, W.C. ${ }^{\mathrm{a}, *}$; Sebastiani ${ }^{\mathrm{b}}$,G.;Van den Boogaard,A.H. ${ }^{\mathrm{c}}$,The technology of
Incremental Sheet Forming-A brief review of the history, ${ }^{\mathrm{a}}$ CORUS RD\&T, PO Box 10.000, 1970 CA IJmuiden, The Netherlands; ${ }^{\mathrm{b}}$ Institute of Forming Technology and Lightweight Construction (IUL), Technische Universität Dortmund, Baroper Strasse 301, 44227 Dortmund, Germany; ${ }^{\circ}$ University of Twente, PO Box 217, 7500 AE Enschede, The Netherlands (2010).

[6]. Le,V. S. ${ }^{1 *}$; Nguyen,T. N. ${ }^{2}$;Le, K. D. ${ }^{2}$; Ghiotti ${ }^{1}$,A. ;Ucchetta,G. $\quad{ }^{1}$,Incremental sheet forming of glass mat thermoplastic - ${ }^{1}$ DIMEG - University of Padova - Via Venezia, 1, 35131 Padova, Italy; ${ }^{2}$ Department of Machine Design HoChiMinh City University of Technology, Viet Nam.

[7]. Pedro Pablo Rrodriguez - Incremental sheet forming Industrial applications International seminar on Novel sheet metal forming technologies, Finland, (2006).

[8]. Lotta Lamminen, Boel Wadman, Rein Küttner, Torgeir Svinning - Prototyping and low volume production of sheet metal components - Helsinki University of Technology, Finland. 